\section{Hargita Horvat Futo*}

Filozofski fakultet

Univerzitet u Novom Sadu

Emeše Mate

Visoka škola strukovnih studija za vaspitače i

trenere, Subotica
UDK: $81 ' 221: 159.937 .51$

$371.3: 316.77$

DOI: $10.19090 /$ gff.2020.1.97-108

Originalni naučni rad

\title{
NEVERBALNA KOMUNIKACIJA BOJAMA U UČIONICI ${ }^{* *}$
}

Studija se bavi problematikom uređenja enterijera i odabira boja $u$ prostoru za učenje $u$ obrazovno-vaspitnim institucijama sa ciljem da se formira savremena podsticajna sredina $u$ kojoj će dete biti motivisano za istraživanje, učenje, rad i igru. Prve utiske o novoj sredini dete stvara i na osnovu boja i osvetljenja prostora u kojem se nalazi. Boje mogu da utiču na ponašanje i raspoloženje dece, zato učionice treba da imaju adekvatan kolorit. Deca i pomoću boja komuniciraju sa okolinom; boje pomažu odraslima da razumeju njihov simbolički jezik i pomoću tih spoznaja planiraju dnevne aktivnosti u predškolskim ustanovama. U istraživanju koje je sprovedeno 2018. godine u Evropskom Valdorf centru u Engelbergu prikupljeni su podaci o dominantnim bojama odela dece od 3 do 7 godina, a zabeleženi su i njihovi odgovori o razlozima odabira odgovarajuće boje. Praćena je i neverbalna komunikacija između boja odevanja deteta i dominantnih boja kutića dnevnog boravka, kao i metode izbora aktivnosti i nastavnih tema na osnovu boja dečje garderobe. Drugo istraživanje u vezi sa bojama sprovedeno je u vrtićima u Mađarskoj i Srbiji sa ciljem istraživanja asocijacija u vezi sa zelenom i crvenom bojom. Predškolska ustanova sve više predstavlja detetov životni prostor koji treba prilagoditi njegovim potrebama, a cilj rada je istaknuti važnost prostorno-materijalnog okruženja u obrazovanju.

Ključne reči: predškolske ustanove, prostorno okruženje, stimulativna sredina, kolorit, simbolički jezik dece, neverbalna komunikacija bojama, socijalne interakcije, skrivalice.

\section{FORMIRANJE SAVREMENE PODSTICAJNE SREDINE ZA UČENJE - ULOGA BOJA}

Celokupni kontekst detetovog odrastanja treba da razvija i podržava njegove višestruke inteligencije i veštine u ugodnom i prijateljskom okruženju: „U

\footnotetext{
*horvathfuto@ff.uns.ac.rs, turulemese12@gmail.com

** Studija je nastala u okviru projekta Diskursi manjinskih jezika, književnosti i kultura u jugoistočnoj i srednjoj Evropi (br. 178017) Ministarstva prosvete i nauke Republike Srbije.
} 
takvom okruženju deca mogu birati uvek dostupne i zanimljive materijalne podsticaje i njima se slobodno baviti. Podsticajno okruženje je zanimljivo, dinamično i inovativno te podstiče dečje čuđenje, radoznalost i uzbuđenje u otkrivanju njima novih i interesantnih stvari" (Ćamović, 2014: 124). Osmišljavanje takvog prostora - njegovo projektovanje, građenje i unutrašnje uređivanje - zahteva saradnju i timski rad arhitekata, projektanata, vaspitača i ostalih nadležnih osoba, a najkorisniji proces oblikovanja prostora je onaj koji se koristi bojama, svetlom, zvukom i mirisom, jer to korespondira sa dečjim kognitivnim procesima (Zini, 2006: 15). Postoji tesna veza između doživljenog ambijenta, odnosno utiska o konkretnom objektu ili prostoriji i komunikacijskih procesa koji se formiraju u njima. Senzibilitet pomoću kojeg procenjujemo fizičku sredinu često deluje podsvesno: uvek postoji podsvesni „osećaj” u vezi sa nekim objektom, odnosno sa uređenjem njegovog enterijera ili eksterijera. Na kvalitet rada pojedinca utiče dizajn sredine, način na koji je prostor organizovan i uređen: i na polju obrazovanja postoji suptilna veza između fizičkog okruženja u kojem se uči i kvaliteta predškolskog i školskog života. Uređenje prostora za boravak dece, zajedničkih prostorija vrtića i školskih učionica treba da podstiče, a ne da sputava komunikaciju (Holik-Sanda, 2015). Prema opisu Okvira nacionalnog kurikuluma škola kao sredina za učenje mora da omogući motivisanost učenika za učenje i kreira atmosferu u kojoj učenici stasavaju u aktivne, kompetentne, inicijativne, kreativne i odgovorne ljude: „Sredinu za učenje čini više dimenzija. One se mogu grupisati na različite načine, a za ostvarivanje koncepcije učenja i razvoja posebno su značajne one osnovne: fizička, psihološka, socijalna i pedagoška" (Okvir nacionalnog kurikuluma, 2016: 73). Nacionalni okvir predlaže da prostor bude bezbedan, uredan, čist, prirodnim i veštačkim svetlom dobro osvetljen, provetren, da nije zatrpan starim predmetima i predmetima koji se ne koriste, i da je opremljen nastavnim sredstvima koja su prilagođena uzrastu učenika (Okvir nacionalnog kurikuluma, 2016: 74). Fizička dimenzija školskog prostora ne sme da bude sterilna, hladna, treba je sagraditi i urediti na način da se u njoj mogu koristiti razne tehnike učenja, da boje i forme $u$ njoj omoguće održavanje pažnje učenika, da ih motivišu na aktivno uključivanje $u$ proces učenja. Preporučljivo je da prostor sadrži elemente koji upućuju na tradiciju i kulturu (Faust, 2004: 21). U fizičkom prostoru dekoracija, nameštaj, table sa informacijama, kolorit prenose kodirane poruke, deluju kao elementi neverbalne komunikacije: Ovakve „poruke” se pojavljuju svugde u našem okruženju, ali ih moramo prepoznati u vrtićima i školama, jer u ovim prostorima deca dobijaju najviše stimulacija kroz svakodnevne aktivnosti (Bauer, 1963: 52). Osnovu toplog i prijatnog okruženja za učenje čini harmonija boja. Prilikom izbora boja treba uzeti u 
obzir rezultate istraživanja koja su se bavila uticajem boja na učenje. Najčešće se vaspitno-obrazovne institucije odlučuju za belu boju zidova, iako bela boja ne smanjuje anksioznost, ne stvara atmosferu doma i ne motiviše decu (Mahnke, 1996; Nuhfer). Stručnjaci preporučuju upotrebu raspona hromatskih boja s puno nijansi, što ne znači da zidove treba farbati u crvene, žute i plave boje koje odrasli vrlo često povezuju s decom. Deci treba ponuditi suptilniji i raznovrsniji spektar boja: „On bi trebao uključivati boje koje su međusobno slične, nijansu po nijansu, zavisno o jačini i intenzitetu; onda boje koje stoje u kontrastu i čiji se intenzitet smanjuje kad se nalaze u kombinaciji s komplementarnim bojama. Naglašene boje koje stoje u kontrastu s glavnom šemom boja mogu se koristiti da bi istaknule specifične prostore, područja ili predmete" (Zini, 2006: 17).

Boje utiču na ljudski organizam - neke bude pozitivne osećaje, ne umaraju oko, jačaju volju za učenjem. Istraživanja pokazuju da svetložuta i narandžasta podstiču dobro raspoloženje, predstavljaju boje radosti: „To je najbliža boja svjetlosti. U svojoj najvećoj čistoći, žuta uvijek ima laganu prirodu i odlikuje se jasnoćom, vedrinom i blagim šarmom. U ovoj fazi, to je ugodno kao okruženje, bilo u obliku odjeće, zavjesa, tapeta. Iskustvo pokazuje da žuta boja ostavlja izuzetno topao i ugodan dojam." (Goethe, 2010: 78) Bež pospešuje koncentraciju, nebesko plavo takođe, a služi i za opuštanje, a zelenoplavu i zelenu takođe preporučuju za farbanje zidova učionica. Od četiri zida učionice jedan zid - u koji deca najviše gledaju - treba ofarbati u drukčiju boju, intenzivnijeg ili tamnijeg tona ili u komplementarnu boju. Drugačija je situacija izvan učionica, na hodnicima se puno kreće, tu učenici ne provode više vremena u jednom mestu, zato hodnici mogu da budu raznoliko ofarbani, u više boja, mogu se koristiti i tamniji i življi tonovi, kontrastne boje i tonovi (Molnár, 2008: 10). Boje odeće nikako nisu slučajne, one zavise od ličnog ukusa, od mode, od pripadanja nekoj određenoj subkulturi i od raspoloženja. Boje predstavljaju čovekovu optičku vizit-kartu: „Njima sebe saopštavate svojoj okolini. Svojim bojama vi utvrđujete svoje optičko obeležje. Boje su jedan od prajezika ovog sveta. Preko boja saopštavamo sebe i shvatamo signale koje nam naše okruženje preko njih šalje. Onaj ko razume boje, razume nešto više o ovom svetu" (Folmar, 2011: 9).

\section{PLANIRANJE SADRŽAJA RADNOG DANA U VALDORF OBDANIŠTIMA ZASNOVANO NA NEVERBALNOJ KOMUNIKACIJI BOJA}

Dete veći deo dana provodi u vrtiću, a predškolska ustanova sve više predstavlja detetov životni prostor - dete živi, uči, raste, razvija se i odgaja u 
institucionalnom kontekstu: „Smatra se da razumevanje vaspitno-obrazovne prakse nije moguće postići posmatranjem samo određenih dimenzija konteksta, već da se sve dimenzije moraju posmatrati interaktivno, jer je i njihova pojavnost takve prirode" (Malnar-Punčikar-Štefanec, \& Vujičić, 2012/2013: 4). Svet oko sebe deca percipiraju uronjena u širok spektar nijansi oblika, boja, mirisa, ukusa, taktilnih i svih drugih senzornih stimulansa (podražaja) i informacija. Zato je svakodnevno doživljavanje sveta za dete mnogo sadržajnije i bogatije nego za odrasle: „Ovo bogatstvo doživljaja dete na različite načine interpretira i izražava kroz različite oblike ekspresije. Strategije razumevanja deteta podrazumevaju i savladavanje nekih specifičnih veština: na primer veštinu uspostavljanja različitih modaliteta komunikacije sa detetom, osim one uobičajene, govorne" (Slunjski, 2008: 105). Deca imaju sto jezika, odnosno izražajnih mogućnosti (npr. verbalni, grafički, gestovni jezik) kojima mogu komunicirati, koristeći se odgovarajućim izražajnim medijima (Slunjski, 2008: 105).

Predškolski uzrast je vizuelno najšarenija grupa dece jer su ona najviše sklona da se oblače prema raspoloženju. U izboru odeće boje su dominantne i time deca daju znakove svom okruženju u vidu neverbalnog komunikativnog polja boja (Steiner, 1995: 12). Vaspitači u Valdorf obdaništima ujutro, kad se deca skupe u grupu, proveravaju koje su boje deca izabrala prilikom oblačenja, pa prema tome prave plan rada i određuju prioritete za taj dan (da li će boraviti u prirodi, da li počinju nastavu ritmičkim plesom, pevanjem ili ručnim radom itd.). Ovo neverbalno komunikativno polje sačinjeno od boja dečje odeće u grupi ima svoju neverbalnu komunikativnu interakciju sa bojama osmougaone dnevne sobe Valdorf obdaništa. Boje neverbalnog komunikativnog polja obdaništa iliti osmougaonog dnevnog boravka za decu su unapred određena prema nastavnim jedinicama (Steiner, 1995: 65), harmonizovane su sa sadržajem nastave i kao takve služe za neverbalnu komunikaciju između članova grupe i nastavnog osoblja: u kutiću posvećenom Bogorodici nalaze se ogromne plave svilene marame, tu se slave praznici i održavaju se krugovi tišine posle ispričane bajke, u kutku za devojčice pored lutki i kolica stavljene su roze male svilene marame, u kutku za dečake su drveni brodovi, vozići, pruga i automobili ofarbani u crvenu boju, elementi kuhinje (drveni šporet, drveno povrće, korpe pletene od vrbe) ofarbani su oker žutom, kutak pijace je u nijansi duge (drvena vaga, pult, pamučne pletene životinje i razno povrće izrađeno od drveta), kutak za instrumente (harfa, lira) je dobio boju zlatne svile, u kutku za likovnu umetnost (debele specijalne drvene olovke i pastel krede) dominira ljubičasta boja, a pod kutića za slobodno stvaranje je zelene boje (drvene kocke, grane za građenje, svila, prirodni tekstili, plodovi kao što su kesten i žir, 
školjke, pletene životinje). U Valdorf obdaništu stvoreni su svi uslovi da se dete po unutrašnjoj motivaciji harmonizuje sa nekom određenom bojom. Boja preko „mozga deluje direktno na čovekovu energiju. Na taj način, odgovarajućim izborom boja mogu da se otklone blokade i da energija ponovo slobodno teče. Da se osećamo dobro, lako i poletno" (Folmar, 2011: 12).

Tokom leta 2018. godine (između 20. juna i 18. jula) u nemačkom gradu Engelbergu u Valdorf obdaništu vršile smo istraživanje ${ }^{1}$ o načinu izbora boje prilikom oblačenja dece. Osnovu istraživanja čini Geteova nauka o bojama jer je teorija o bojama Valdorf pedagogije kompatibilna sa teorijom velikog pesnika. U knjizi Zur Farbenlehre (1810) Johan Volfgang Gete je dao naučna objašnjenja šta su boje, proučavao je prirodu, funkciju i psihologiju, odnosno ljudsku percepciju boja:

Budući da boja zauzima tako visoko mesto među prvobitnim fenomenima prirode, nesumnjivo s velikom raznolikošću obavljanja jednostavnog kruga akcija koje mu se stavljaju, nećemo se iznenaditi ako saznamo da to u najčešćim elementarnim manifestacijama, bez obzira na strukturu i oblik materijala, na čijoj površini ga opažamo, ima određeni učinak na osećaj vida, na koji je pretežno tempiran, i kroz njega na mentalno raspoloženje. To delovanje, posebno odvojeno, specifično je, kombinirano - delomično skladno, delom karakteristično, često i neharmonično, ali uvek određeno i značajno, neposredno povezano s područjem morala. Zato se boja, kao element umetnosti, može koristiti za promovisanje viših estetskih ciljeva (Goethe, 2010: 90).

Gete je prvi razlikovao tople i hladne boje, a sa njegovom teorijom su upoznati vaspitači u Valdorf predškolskim ustanovama, i pomoću nje, kroz boju dečje odeće, vrše dekodiranje emocionalnog stanja dece.

Podaci u istraživanju sakupljeni su pomoću intervjua. Deca su odgovarala na sledeća pitanja: Kako si izabrao/la boju odeće ujutru pri oblačenju? Zašto si izabrao baš tu boju? Podaci su sakupljani mesec dana. U istraživanju je učestvovalo dvadeset osmoro dece (16 devojčica i 12 dečaka). Sumirajući odgovore, možemo zaključiti da je izbor boja zasnovan na emotivnoj bazi: npr. „Sija sunce pa sam obukla žuto.” „Pripremamo se za more pa sam obukao plavo.” „Danas idem kod bake, penjaću se na kamaru slame, pa sam obukao plavi overal.” „Rozu sam obukla jer mama kaže da sam u tome lepa. Hoću da budem lepa!” „Crveno sam obukla jer volim jagodu, a jagoda je crvena.” Procentualno izraženo, $0,8 \%$ dece nije znalo da obrazloži zašto su obukli izabranu boju odeće, a 99,02\% je svako jutro obrazložilo

\footnotetext{
${ }^{1}$ Istraživanje je omogućilo Nemačko udruženje „Maria Theresiopolis” iz Subotice.
} 
svoju odluku. Tokom istraživanja smo zapazile da, kada se deca uvrede tokom igre i prekinu igru, u 76\% slučajeva se povuku u onaj kutak koji je ofarban bojom koja je njihova dominantna boja u odevanju tog dana. U kutku ostanu pet do deset minuta i nakon disharmoničnog stanja vraćaju se ponovo u harmonično stanje. Kad uđu u kutak ćute, onda primete igračke iste boje koju imaju na sebi i počnu da se igraju sami. Okruženje vrtića detetu treba da omogući i zadovoljenje potrebe za privatnošću, jer ono ponekad ima potrebu za povremenim izdvajanjem od ostalih, za kratkotrajnim osamljivanjem: „Da bi se deci omogućilo ovakvo povremeno "povlačenje« iz grupnih zbivanja, odgajatelji mogu izgraditi improvizirane kućice skrivalice" (Slunjski, 2008: 24). U skrivalici igra traje 5-8 minuta, nakon toga se deca vraćaju u grupu, i ponovo se uključuju u igru sa ostalom decom.

U letnjem periodu prilikom istraživanja na na deci uzrasta od 3 do 7 godina dominantne boje u odevanju kod devojčica bile su: žuta 22,5\%, šarena $8,5 \%$, ljubičasta $18 \%$, roza $16 \%$, bela $12 \%$, zelena $14 \%$, crvena $5,5 \%$ i plava $3,5 \%$. Kod dečaka u istom uzrastu dominantne boje su: zelena $35,5 \%$, žuta $20,5 \%$, plava $17 \%$, bela $12 \%$, crvena $8,5 \%$ i ljubičasta $6,5 \%$. Za vreme slobodne igre koja traje dva sata devojčice su najčešće boravile u kuhinji $38 \%$, u kutku pijace $28 \%$, u kutku za devojčice $7,5 \%$, za instrumente $8,5 \%$, za likovnu umetnost $11 \%$, za slobodno stvaranje 5\%. Dečaci su najviše vremena proveli u kutku za dečake $45 \%$, u kutku za devojčice $22 \%$, u kutku za pijacu $14 \%$, u delu sa instrumentima 3,5\%, u kuhinji $6,5 \%$, a u kutku za likovnu umetnost $9 \%$.

Prilikom upoređivanja omiljenih boja dece i boja kutkova u kojima provode najviše vremena konstatovali smo njihovo slaganje. Kod devojčica je dominirala žuta boja u odevanju (22,5\%), a u slobodnoj igri najviše vremena su provele u kuhinji (38\%) gde je takođe žuta boja dominantna. Kod dečaka ja vladala zelena boja u odevanju $(35,5 \%)$ i za vreme slobodne igre najviše su boravili u kutku slobodnog stvaranja (45\%) koji je obojen zelenom bojom.

U Valdorf pedagogiji dominantna boja u grupi je merodavna za planiranje nastavnih sadržaja za taj dan (Steiner, 1995: 45). U naznačenom letnjem periodu, kada je istraživanje vršeno, izabrane boje anketirane dece i boje neverbalnog komunikativnog polja dečjeg dnevnog boravka zaista su pomogle da izabrani sadržaji tog dana budu uspešni - deca su bila dobrog raspoloženja i aktivna. Posle dva sata slobodne igre sledio je doručak, pa planirani deo dana. Valdorf vaspitačice su onog dana, kada je najviše devojčica obuklo odeću žute boje, a dečaka odeću zelene boje, izabrale aktivnosti u šumi pored zabavišta gde se nalazi i velika igraonica u pesku. Deo šume pored obdaništa pretvoren je u interaktivnu površinu za razonodu sa drvenim spravama za kreativno igranje i za fizičko vežbanje koje 
uglavnom koriste dečaci, a peščani deo sa puno posuda za kuvanje i pečenje devojčice. Svaki mali kutak u zatvorenom prostoru zabavišta ima svoj paralelni prostor u prirodi sa puno više detalja za razvijanje slobodnog duha i kreativne mašte (Streit, 1990: 25). Žuta boja je boja topline, najblistavije zrači svetlost, deluje podsticajno, utiče na stvaralački i intelektualni rad, na komunikaciju, podiže energiju i raspoloženje (Vollmar, 2009: 32-37). Zelena je boja prirode, povezujemo je se livadom i šumom. Simbolizira plodnost, rast, život i harmoniju (Vollmar, 2009: 224), zato su dečaci izabrali tog dana aktivnost u prirodi, i u okviru dramske pedagogije odigrali su bajku Pelles neue Kleider u dvorištu gazdinstva sa malim ovcama.

\section{DA LI MOŽEMO NA PODSVESNOM NIVOU MENJATI UKORENJENO, TRADICIONALNO ZNAČENJE BOJA?}

Boje su oduvek imale važnu ulogu u komunikaciji, jer deluju direktno: „Reči se moraju prevesti u slike u mislima. Te slike moraju biti sklopljene, organizovane i kategorizovane da rečima daju značenje. Zatim sledi emotivni odgovor, koji može pokrenuti i fizički odgovor. Boja preskače sve ove faze i direktno budi emocije, stvarajući psihološki odgovor" (Trandafilović, 2006: 77). U svakom od nas postoji podsvesna antropološka konstanta tumačenja boja: „Kada vidimo nekoga u ružičastoj odeći ili okruženju, smatramo ga više prijateljski nastrojenim nego da je reč o nekoj drugoj boji. Osobu u crvenom smatramo eksplozivnom i aktivnom, a nekoga u sivom pasivnim i neodređenog stava" (Mirkov, 2012: 125). Slika koje jedno društvo formira o čoveku i sistem informacija društva se sa vremena na vreme menjaju, a svako doba ima svoje specifične karakteristike. Purpurna i zlatna boja su oduvek bile boja vladara. Kada su se mađarska plemena nastanila u Panonskoj niziji, u svom novom domu su morala zameniti svoju staru veru rimokatoličkom da bi tadašnja evropska politika prihvatila nove stanovnike. Prvi kralj Mađarske Sveti Stefan (Szent István) polagao je zakletvu 1000. godine u odeći koja je odgovarala evropskom odevanju i bojama ceremonijalnog vladarskog kostima toga doba: kralj je bio ogrnut plaštom purpurne boje, mada je po starom mađarskom običaju trebalo da nosi ogrtač zelene boje (boja vođa, vezira) u kombinaciji sa narandžastocrvenom bojom (Sudár-Petkes, 2014: 12). Kralj Stefan se ispred naroda ponovo krunisao po dotadašnjim važećim pravilima u zeleno zlatnožutom plaštu, i tek tada je bio prihvaćen kao kralj od strane svog naroda (Pap, 1999: 58). Ukrasni i modni neverbalni simboli ,posledica su iskonskog nastojanja čoveka da u očima drugih stvori bolju predstavu o sebi. Onim što je izveo na svom telu ili obukao on emituje određenu poruku. Ukrašeno 
telo ili definiše status ili izražava nameru" (Radojković-Miletić, 2008: 49). Došlo se do empirijske potvrde da postoji apstraktan, simboličannivo značenja boja: „Na osnovu toga je zaključeno da se radi o generalnom fenomenu, prisutnom kod svih ljudi, a koji verovatno zadire u domen značenja pojmova. Potvrdila se ranije izneta pretpostavka da je svaka boja pojedinačno prilično složena i osobena u svojoj simbolici. Gotovo da joj se pridaje karakter" (Trandafilović, 2006: 78).

Interesovalo nas je koje slobodne asocijacije imaju deca predškolskog uzrasta koja još ne poznaju istoriju i simboliku boja u vezi sa zelenom i crvenom bojom. Istraživanje je sprovedeno u dve države: u Mađarskoj i u Srbiji. Obe grupe dece su mešovitog uzrasta od 3,5 do 6,5 godina, mađarske nacionalnosti, devojčice i dečaci u istoj razmeri. Broj ispitanih je dva puta po 22 osobe. Tri pitanja su vaspitačice pročitale deci i zabeležile odgovore.

\section{Upitnik}

1. Pogledaj dete na obe slike! U koje dete bi imao potpuno poverenje kao vođu, koji od njih dvojice bi bio dobar predvodnik? Na koje dete bi se mogao osloniti, na dete sa slike A ili sa slike B?

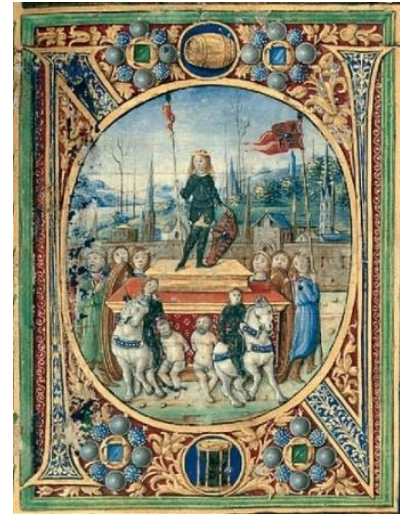

A) Matija Korvin

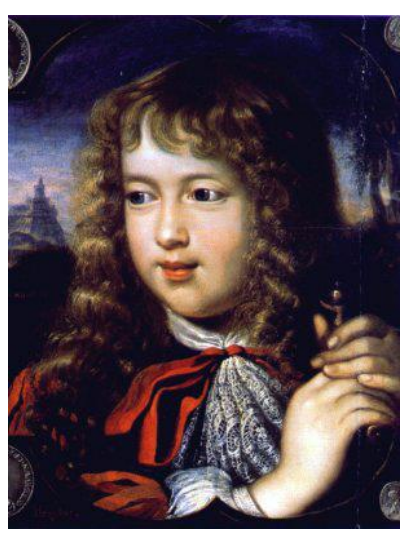

B) Luj XIV

2. Sa kojim detetom bi se rado igrao i čega? Da li bi se radije igrao sa detetom sa slike A ili sa slike B?

3. Slobodne asocijacije dece:

a) Zelena boja:

b) Crvena boja: 


\section{Obrada upitnika}

Deca iz Mađarske su u 98\% slučajeva imala poverenje u dete sa slike A, dok se većina dece iz Srbije (86\%) odlučila za dete sa slike B. Na drugo pitanje su deca iz Mađarske dala sledeće odgovore: A - igrali bi se žmurke, mazili bi zajedno životinje, jahali bi zajedno, radili bi premet strance na travi, kampovali bi u šumi, osnovali bi dečji orkestar sa njim ... Sa detetom sa slike B bi se mačevali zajedno, putovali bi brodom i vozom, slušali bi muziku zajedno. Deca iz Srbije su odgovorila: A - lovili bi zajedno, igrali bi Star Vors (Star Wars), mazili bi šumske životinje, a sa detetom sa slike B - mačevali bi se, svirali bi zajedno gitaru, kuvali bi.

$\mathrm{Na}$ treće pitanje u vidu slobodnih asocijacija smo dobili sledeće odgovore od dece iz Mađarske: zelena boja - trava, šuma, sloboda, proleće, život, Mazsola (prase iz crtanog filma zelene boje); crvena boja - radost, jagoda, trešnja, paradajz, auto. Deca iz Srbije su u vezi sa zelenom bojom imala sledeće asocijacije: zelena boja - polje, planina, šuma, Sprite (sprajt bezalkoholno piće), OTP banka, kasarna; crvena boja - krv, Sunce, vatra, paprika, Ferari auto.

Možemo konstatovati da su deca dala različite odgovore jer su različito doživela likove sa slika koji su bili obučeni u odeću zelene i crvene boje. Naime, boja njihove odeće uticala je na njihove odgovore. Kulturno nasleđe naroda $u$ značajnoj meri utiče na emotivni sadržaj boja tog naroda. Određivanje nacionalne simbolike boja zahtevalo bi posebno istraživanje.

\section{ZAKLJUČAK}

Celovitost Valdorf pedagogije bazirana je na ritmu koji karakteriše razvoj žive prirode, pa tako i svakog čoveka. Njen pedagoški plan je nepromenjen već 100 godina. Neverbalna komunikacija, koja se svakog dana odvija između dece i pedagoga, putem sveta simbola boja, pedagozima praktičarima našeg vremena pruža takođe stogodišnje izuzetno uspešno praktično iskustvo. Simbolika boja kod dece daje polaznu tačku pedagozima pri izboru sadržaja, odnosno prostora grupnih aktivnosti. U prostoru se smanjuju napetost, frustracija i prigušene emocije. Harmoničan, punovredan razvoj ličnosti dobija prostora, zahvaljujući tome što obraćamo pažnju na neverbalne znake, u ovom slučaju na boje. Povezivanje emocionalnih sadržaja i boja radi se na osnovu Geteove teorije o bojama. Znanje o uticaju boja na emocionalni i moralni razvoj dece moglo bi se u većoj meri koristiti i u predškolskoj nastavi u Srbiji. Deca predškolskog uzrasta ne umeju u potpunosti da verbalizuju svoja osećanja, probleme, nedoumice i dileme, zato je važno da 
odrasli (roditelji, bake i dede, vaspitači itd.) obrate pažnju na njihovo korišćenje boja u svakodnevnim aktivnostima. Veliki broj psiholoških testova pokazuje da boje znatno utiču na raspoloženje deteta, na njegovu energiju i vitalnost, pa se preporučuje da odrasli koji žive i rade sa decom svesno biraju boje detetovog okruženja kako bi se ona osećala sigurno. Na osnovu istraživanja koje je opisano u radu nastala je i kreativna holistička radna sveska ZlatOboj za uzrast od 6 do 9 godina (Mate-Hilčenko-Hilčenko \& Morić, 2020). U Srbiji se polako počinje sa primenom Valdorf sistema obrazovanja - $\mathrm{u}$ Beogradu je formirano nekoliko vrtića i grupa koje se bave učenjem i razvojem predškolske dece uz korišćenje principa Valdorf pedagogije. Trebalo bi takođe raditi na upoznavanju i prihvatanju alternativnih metoda kroz stručna usavršavanja, radionice i stručne ekskurzije, kao i na njihovom integrisanju u nastavu, samostalno ili u kombinaciji sa tradicionalnim metodama.

Hargita Horvat Futo, Emeše Mate

\section{NONVERBAL COMMUNICATION USING COLOURS IN THE CLASSROOM}

\section{Summary}

In the framework of the 100 year anniversary of Waldorf pedagogy in the field of kindergarten pedagogy, a month long research was carried out in Engelberg (Germany), in the world centre of Waldorf pedagogy, from the second half of June 2018 till the first half of July. The aim of the first research was the examination of non-verbal communication among the students and the teacher using the symbolism of colours, in order to create the most harmonious communication-information space. The colour structure of space with the colours of toys made from natural materials represent all primary colours of the rainbow. The colour world of children's cloths makes alive the communicative space being actualized at the time. Kindergarten teachers base the content and site of collective occupations upon this non-verbal communication. The second research was related to the colour symbolism of nations. Namely, the focus was on communicative content associated by certain nations through drawings from national cultural heritage in case of identical colours. Goethe considered Theory of Colours the most significant work of his own oeuvre. The European scientific community and Waldorf pedagogy experts also consider Goethe's Theory of Colours as their base. This research also relies on this source. The chapter entitled Allegorical, symbolic, mystic use of the colour frames the spine line of this research: all seven colours are present, since this choice harmonises the most with the basic principles of Waldorf pedagogy: with the completeness of life and physiological processes typical of all living creatures and with the entire human image (body-soul-spirituality). The pace of the curriculum applies the self-motivational method synchronized with the developmental 
peculiarities typical of each individual (everybody competes with one's own achievement, everybody has to exceed their own capacity and notthe other's ).

This non-verbal communicative informational space between the child and the teacher is the allegorical, symbolic and mystic mediation of colours that carry morals and spirituality shaping weight. It is present in Waldorf kindergarten centre in various forms (Frei Waldorfkindergarten Engelberg): in all volumes of the centre's library, the octagonal space of the group room, the exterior and interior kindergarten community spaces.

Based on Goethe's theory of colours, the kindergarten teachers are familiar with the ancient collective ethical and emotional duration of colours, and easily decode the children's emotional state and moral courses on a given day by their clothes. The ancient collective principle of consciousness and the emotional harmonisation function instinctively when it comes to children, and the self-correction processes occur unconventionally. It is necessary to emphasize here the significance of the emotional harmonisation processes happening without directed activity, which is the physical peculiarity of every human being. The research presents these non-verbal commu nicativeprocesses of colours on the basis of allegorical andsymbolic meaning in the process of selecting daily activities by kindergarten teachers, and the t non-verbal role colours play in children's ethical and emotional harmonisation processes. The non-verbal communicative and emotional effect, as well as the effect colours have on the development of the moral, can be applied to the Serbian educational model as well.

Keywords: pre-school institutions, furnishing of the room, stimulative environment, colour world/colouring, child's symbolic language, non-verbal communication with colours, social interactions, hiding corners

\section{LITERATURA}

Bauer, Eugen (1963). Schulbau pädagogisch gesehen. Schriftenreihe für die praktische Schularbeit. Villingen: Neckar-Verlag.

Ćamović, Dž. (2014). Odgajatelji u procesu iskustvenog učenja: od refleksivne prakse do poticajnog vrtićkog okruženja za djecu i odrasle. U: Hrvatić N. et al. (ured.) (2014). Pedagogija, obrazovanje i nastava. Mostar: Sveučilište, Fakultet prirodno-matematičkih i odgojnih znanosti. 123-130.

Faust, G. (2004). Welche Räume braucht die Grundschule? Überarbeitete Fassung des Vortrags im Rahmen der Ausstellung ,,Schulbauten. Stand der Dinge”. Zürich. https://www.uni-bamberg.de/fileadmin/uni/fakultaeten/ppp_ lehrstuehle/grundschulpaedagogik/doks/vortrag_schulbauten_zuerich04.pdf Folmar, K. (2011). Velika knjiga o bojama. Beograd: Laguna.

Goethe, J. V. (2010). Szintan. Budapest: Genius. 
Holik I.-Sanda István D. (2015). Tanári kommunikáció. Budapest: Óbudai Egyetem. https://www.tankonyvtar.hu/hu/tartalom/tamop412b2/20130002_tanari_kommunikacio/tananyag/JEGYZET-05-

1.2._A_tanari_kommunikacio_al.html

Mahnke, F. H. (1996). Color, Environment and Human Response. New York: John Wiley \& Sons.

Malnar, A.-Punčikar, S.-Štefanec, A.-Vujičić, L. (2012/2013). Poticajno okruženje: izazov za suradnju i istraživanje djece i odraslih. Dijete, vrtić, obitelj, 70, 4-7.

Mate, E.-Hilčenko, Ch.-Hilčenko, S.-Morić, M. (2020). ZlatOboj. Subotica: Visoka škola strukovnih studija za obrazovanje vaspitača i trenera,

Mirkov, L. (2012). Neverbalna komunikacija bojama u javnom nastupu. CMčasopis za upravljanje komuniciranjem, 25, 125-142.

Molnár Gy. (2008). A 21. század iskolájának berendezése. U: Kárpáti A.- Molnár Gy.- Tóth P.- Főző A. L. (szerk.) (2008). A 21. század iskolája. Budapest: Nemzeti Tankönyvkiadó.

Nuhfer, E. B.: Some Aspect of an Ideal Classroom: Color, Carpet, Light and Furniture. http://www.isu.edu/ctl/nutshells/IdealClass_files/IdealClass.html

Okvir nacionalnog kurikuluma - osnove učenja i nastave (2016). https://obrazovanje.org/rs/uploaded/dokumenta/Okvir-nacionalnogkurikuluma_Osnove-ucenja-i-nastave.pdf

Pap G. (1999). Hazatalálás. Müvelödéstörténeti irások. Budapest: Püski.

Radojković, M.-Miletić, M. (2008). Komuniciranje, mediji i društvo. Beograd: Učiteljskifakultet.

Slunjski, E. (2008). Dječji vrtić zajednica koja uči-mjesto dijaloga, suradnje $i$ zajedničkog učenja. Zagreb: Spektar Medija.

Steiner, R. (1995). Az emberi temperamentumok titkai. Budapest: Jáspis Kiadó.

Streit J. (1995). Nevelés, iskola, szülöi ház és a Steiner pedagógia. Budapest: k.n.

Sudár B.-Petkes Zs. (2014). A honfoglalók viselete. Magyar östörténet 1. Budapest: Helikon Kiadó-MTA BTK Magyar Östörténeti Témacsoport.

Trandafilović, I. (2006). Ime, logo, boja. Beograd: BIGZ.

Vollmar, K. (2009). Das große Buch der Farben. Krummwisch: Königsfurt-Urania Verlag.

Zini, M. (2006). Dijete, vrtić, obitelj. Časopis za odgoj i naobrazbu predškolske djece namijenjen stručnjacima i roditeljima, 44, 15-17. 